\title{
PRODUÇÃO DE BIODIESEL CATALISADA POR LIPASES SOLÚVEIS: INFLUÊNCIA DO EXCESSO DE METANOL E DA CONCENTRAÇÃO DE ÁGUA NA REAÇÃO
}

\author{
D. V. ROSSET ${ }^{1}$, J. H. C. WANCURA ${ }^{1}$, M. A. MAZUTTI ${ }^{1}$ e S. L. JAHN ${ }^{1}$ \\ ${ }^{1}$ Universidade Federal de Santa Maria, Departamento de Engenharia Química \\ E-mail para contato: danielarosset@hotmail.com
}

\begin{abstract}
RESUMO - Apesar das inúmeras vantagens apresentadas pela catálise enzimática, a inativação da enzima quando em contato com o metanol segue como o principal inconveniente do processo. Nesse contexto, o objetivo do trabalho foi investigar a influência do excesso de metanol e da concentração de água utilizados na reação de transesterificação para produção de biodiesel catalisado pela lipase solúvel Thermomyces lanuginosus. A faixa de excesso molar de metanol analisada variou de 3:1 a 6:1, enquanto que a concentração de água adicionada a reação foi de $0 \%$ a $12 \%(\mathrm{~m} / \mathrm{m})$. Estas variáveis mostraram ser fatores significativos na questão de perda da atividade catalítica da lipase e, consequentemente, no rendimento de biodiesel do processo analisado. $\mathrm{O}$ maior rendimento de biodiesel observado foi de $86,4 \%$ quando se utilizou uma temperatura reacional de $35^{\circ} \mathrm{C}$, uma carga de catalisador de 1\%, um excesso de metanol de 4,5:1 e uma concentração de água no meio reacional de 9\%, após 8 horas de reação.
\end{abstract}

\section{INTRODUÇÃO}

Com a iminente diminuição das reservas de combustíveis fósseis, o biodiesel se consolidou nos últimos anos como uma interessante alternativa para a substituição do diesel de petróleo (SAYID ABDULLAH et al., 2017). O processo para a produção de biodiesel baseia-se em uma reação de transesterificação, na qual são utilizados óleo vegetal (ou gordura animal) e um álcool de cadeia curta na presença de um catalisador. Em escala industrial, atualmente, a catálise alcalina é a mais empregada, destacando-se, principalmente, pela alta taxa de conversão do processo em curtos intervalos de tempo (BASKAR e AISWARYA, 2015). Entretanto, esta rota apresenta alguns inconvenientes como uma elevada demanda energética, a geração de grande quantidade de resíduos provenientes das etapas de lavagem do produto e a necessidade de utilizar uma matéria-prima com baixos teores de ácidos graxos livres a fim de evitar reações secundárias, como a saponificação (SOUSA et al., 2015).

Como alternativa ao método tradicional, a catálise enzimática surge como uma técnica capaz de contornar os inconvenientes gerados pela catálise básica já que as lipases, por apresentarem alta especificidade, não catalisam reações laterais o que elimina a formação de subprodutos indesejados (MAGALHÃES, 2014). A utilização de lipases como catalisadores apresenta algumas vantagens a destacar a menor demanda energética do processo já que as condições reacionais são mais brandas do que na catálise alcalina e a capacidade das lipases em converter na mesma etapa os triglicerídeos e ácidos graxos livres presentes na matéria- 
prima em biodiesel, permitindo a utilização de matérias-primas com elevados índices de acidez (BASKAR e AISWARYA, 2015). No entanto, a catálise enzimática também apresenta desvantagens como uma baixa taxa reacional, o elevado custo das enzimas e a perda da atividade da lipase quando em contato com metanol (CHRISTOPHER et al., 2014). Grande parte dos trabalhos empregando enzimas utilizam lipases suportadas em matrizes inorgânicas. Entretanto, a fim de compensar o elevado custo destes suportes, o número de reusos da enzima deve ser elevado, comprometendo a capacidade catalítica da lipase e o rendimento de biodiesel (CESARINI et al., 2013). Uma das alternativas a esta técnica consiste na utilização de lipases em sua formulação líquida, produto recentemente lançado pela empresa Novozymes. Por se tratar de um produto novo, são poucos os relatos encontrados na literatura com relação a sua utilização. Algumas informações relevantes não são disponibilizadas como as condições reacionais que favoreçam a atividade catalítica desta enzima e, sobretudo, que minimizem os efeitos inibitórios causados pelo metanol a lipase.

O objetivo do trabalho foi investigar a influência do excesso de metanol e da concentração de água presente no meio reacional sobre o rendimento de biodiesel obtido através de uma reação de transesterificação do óleo de soja, utilizando como catalisador a formulação líquida da lipase Thermomyces lanuginosus.

\section{MATERIAL E METÓDOS}

\subsection{Materiais}

Para a realização dos experimentos foram utilizados como reagentes óleo de soja degomado fornecido pela Olfar Alimento e Energia S/A (Erechim, Brasil), metanol (SigmaAldrich, Alemanha) e como catalisador a formulação líquida da lipase Thermomyces lanuginosus - nome comercial Callera ${ }^{\mathrm{TM}}$ Trans L - produzida pela Novozymes (Dinamarca). Para a análise cromatográfica, foram utilizados isoctano, tricosanoato de metila e um padrão composto de uma mistura contendo 37 ésteres metílicos (Sigma-Aldrich, Alemanha).

\subsection{Métodos}

$\mathrm{O}$ aparato experimental utilizado nos ensaios consistiu em um balão de fundo redondo de $250 \mathrm{~mL}$ imerso em um banho de água e conectado a um condensador de refluxo, interligando-o a um sistema de refrigeração. Esse sistema foi mantido sob agitação magnética constante e aquecimento, sendo a temperatura reacional mantida constante através da ação de um controlador de temperatura.

Em todos os experimentos a massa de óleo de soja utilizada foi de $80 \mathrm{~g}$, a temperatura reacional foi mantida em $35^{\circ} \mathrm{C}$, a carga de lipase de $1 \%(\mathrm{~m} / \mathrm{m}$ em relação a massa de óleo usada) e a agitação do sistema fixa em $300 \mathrm{rpm}$. Na investigação do efeito do metanol foram empregadas relações molares metanol:óleo de 3:1, 3,75:1, 4,5:1, 5,25:1 e 6:1, mantendo o teor de água em $6 \%(\mathrm{~m} / \mathrm{m}$ em relação a massa de óleo de soja utilizada). Já na investigação da influência da concentração de água destilada na reação, as quantidades de água avaliadas foram $0 \%, 3 \%, 6 \%, 9 \%$ e $12 \%(\mathrm{~m} / \mathrm{m})$, mantendo fixa a relação molar metanol:óleo em 4,5:1.

O procedimento experimental adotado consistiu em adicionar o óleo de soja e a enzima ao balão, o qual foi acoplado ao condensador de refluxo e imerso no banho de água para 
aquecimento até a temperatura de reação. Após atingir a temperatura pré-determinada, o metanol diluído em água destilada foi adicionado em uma única etapa ao sistema préaquecido, momento considerado como início da reação. Todos os experimentos foram conduzidos por 8 horas de reação. As amostras coletadas foram analisadas por cromatografia gasosa utilizando-se de um cromatógrafo modelo Shimadzu - GC-2010 Plus equipado com detector de ionização de chama (FID). A separação dos componentes foi realizada por uma coluna Zebron ZB-WAX, com 30m x 0,32mm I.D x 0,25 $\mu \mathrm{m}$.

\section{RESULTADOS E DISCUSSÃO}

\subsection{Identificação dos ésteres formados por cromatografia gasosa}

Um cromatograma típico obtido pela análise das amostras de biodiesel é apresentado na Figura 1. A identificação dos compostos foi realizada através da comparação entre os cromatogramas das amostras coletadas e o cromatograma de um padrão externo composto de uma mistura de 37 ésteres metílicos (de C14:0 ao C24:0), previamente analisados sob mesma metodogia cromatográfica. $\mathrm{O}$ rendimento de biodiesel foi calculado através da quantificação das áreas dos picos majoritários de cada componente apresentado na Tabela 1, na qual o tricosanoato de metila é o padrão interno empregado para quantificação dos ésteres formados.

Tabela 1 - Identificação dos componentes presentes nas amostras

\begin{tabular}{|c|c|c|}
\hline Tempo de retenção (min) & Estrutura Química & Componente \\
\hline 12,06 & C16:0 & Palmitato de Metila \\
\hline 17,01 & $\mathrm{C} 18: 0$ & Estearato de Metila \\
\hline 17,74 & $\mathrm{C} 18: 1$ & Oleato de Metila \\
\hline 19,29 & $\mathrm{C} 18: 2$ & Linoleato de Metila \\
\hline 21,61 & $\mathrm{C} 18: 3$ & Linoleneato de Metila \\
\hline 38,15 & $\mathrm{C} 23: 0$ & Tricosanoato de Metila (padrão interno) \\
\hline
\end{tabular}

Figura 1 - Cromatograma obtido a partir da análise das amostras de biodiesel.

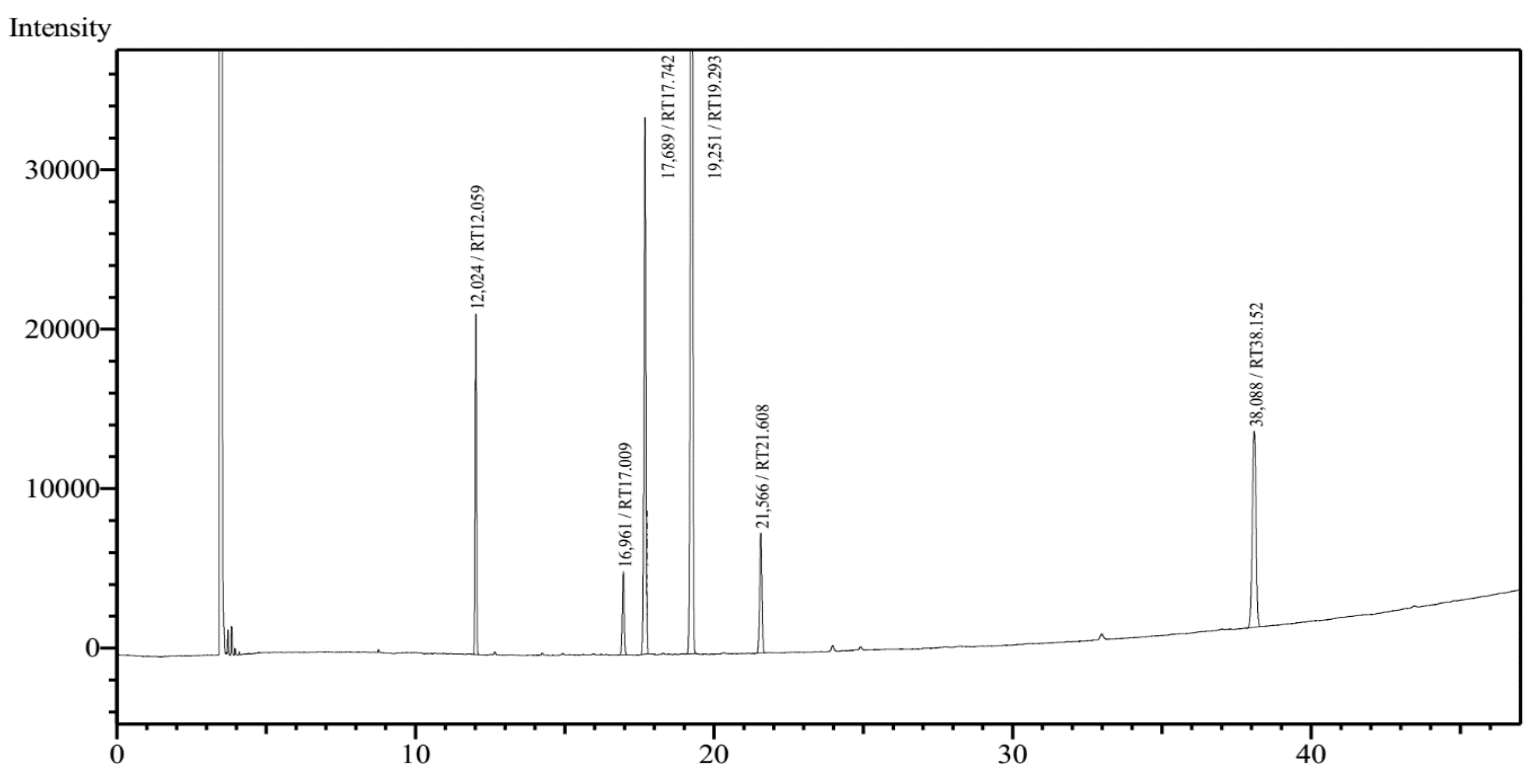




\subsection{Influência do excesso de metanol na reação}

Estequiometricamente, a reação de transesterificação requer 3 mols de metanol para cada mol de triglicerídeo presente no óleo de soja. Entretanto, como a reação de transesterificação é reversível, é necessário um excesso de metanol para deslocar o equilíbrio da reação em direção aos produtos. Pela análise da Figura 2, é possível verificar que o aumento do excesso molar de metanol é benéfico para a atividade da lipase e, consequentemente ao rendimento de biodiesel, atingindo um ápice para uma relação molar metanol:óleo de 4,5:1. Valores superiores a este resultaram em um decaimento no rendimento de biodiesel. Este comportamento pode ser atribuído a um maior efeito inibitório do álcool sobre a lipase, acelerando a desnaturação das proteínas que compõem esta enzima e, consequentemente, prejudicando o rendimento do processo. Comportamento semelhante foi verificado por Nordblad et al. (2014), que relata prejuízo à ativação interfacial da lipase Callera $^{\mathrm{TM}}$ Trans L quando há um aumento na concentração de metanol na reação.

Figura 2 - Influência do excesso molar de metanol no rendimento de biodiesel.

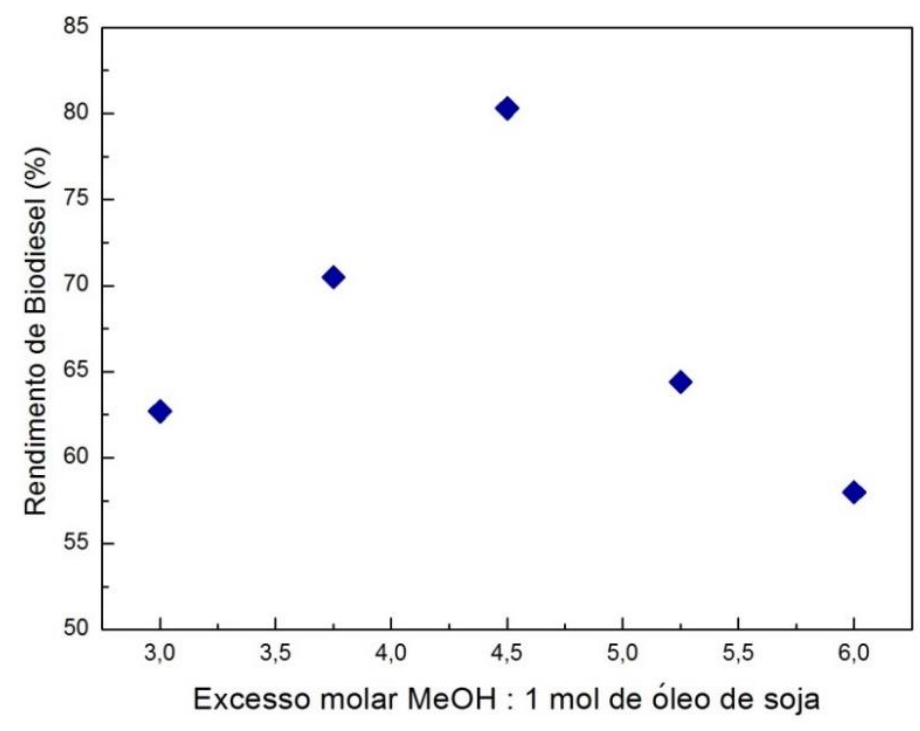

\subsection{Influência da concentração de água na reação}

A influência da concentração de água sobre a atividade enzimática foi investigada, variando a concentração de água adicionada no meio de $0 \%$ a $12 \%$, conforme apresentado na Figura 3. Tomando como referência o rendimento obtido no ponto inicial (37,3\%), no qual não foi incorporada água ao sistema, é possível constatar que a atividade enzimática foi fortemente influenciada pela concentração de água adicionada ao meio reacional, atingindo um ápice com a adição de $9 \%(\mathrm{~m} / \mathrm{m})$ de água - rendimento de biodiesel obtido de $86,4 \%$. Estes resultados são um indicativo de que a presença de água no meio reacional é necessária para minimizar o efeito inibitório do metanol sobre a lipase. Entretanto, o teor de água no sistema não pode ser muito elevado já que poderá ocorrer o favorecimento da reação de hidrólise dos ácidos graxos em detrimento da reação de transesterificação, comportamento observado quando se adicionou $12 \%$ de água ao sistema e o rendimento de biodiesel decaiu para 65,9\%. Situação semelhante foi relatada por Cesarini et al. (2013). 
Figura 3 - Influência da concentração de água no meio reacional.

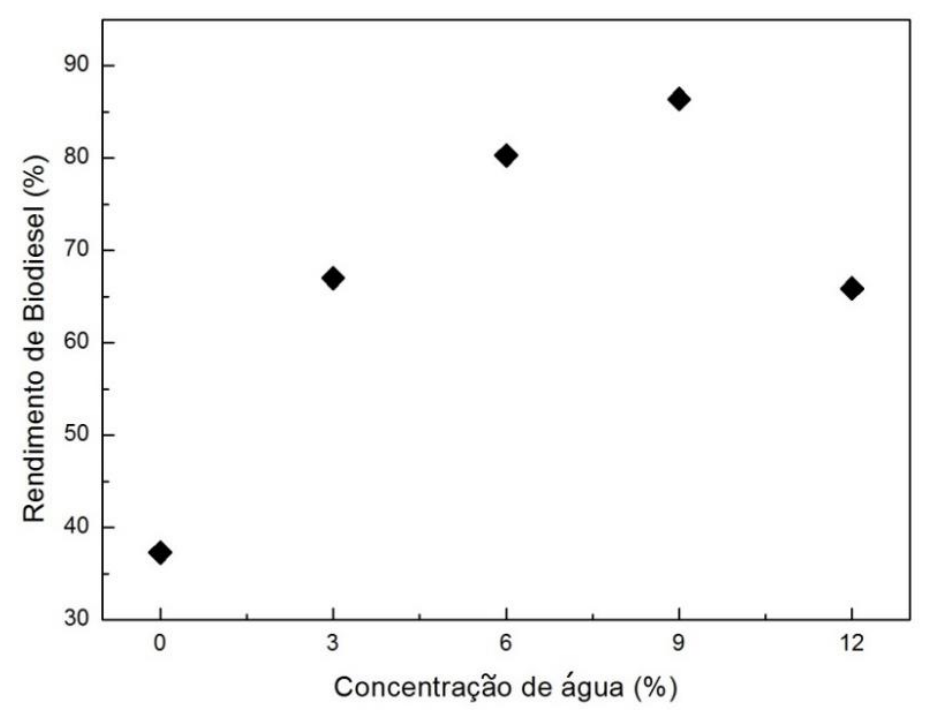

A Figura 4 representa a cinética reacional para as concentrações de água adicionadas ao sistema de $3 \%, 6 \%$ e $9 \%(\mathrm{~m} / \mathrm{m})$. É possível observar que, nos estágios iniciais da reação, o rendimento de biodiesel é afetado de forma mais acentuada pelo aumento da concentração de água na reação, uma vez que o mecanismo de atuação das lipases baseia-se na ativação interfacial, o qual é favorecido pelo aumento da concentração de água no sistema. Com o andamento da reação, o incremento no rendimento de biodiesel para a reação conduzida com $9 \%$ de água foi inferior ao verificado para 3\% e 6\%. Este resultado pode ser atribuído à redução na concentração de metanol, o que provocou uma queda na taxa reacional. Para todas as concentrações de água analisadas, com o decorrer da reação, o efeito inibitório do metanol provocou uma diminuição na atividade da lipase, sendo esta menos pronunciada ao se utilizar $9 \%$ de água. Este comportamento, em tese, pode ser atribuído a maior diluição do metanol no meio reacional, reduzindo o efeito inibitório do álcool e favorecendo a atividade da enzima.

Figura 4 - Análise cinética da influência da concentração de água. Condições utilizadas: $\mathrm{T}=35^{\circ} \mathrm{C}, \mathrm{M}: \mathrm{O}=4,5: 1$ e $1 \%$ de catalisador.

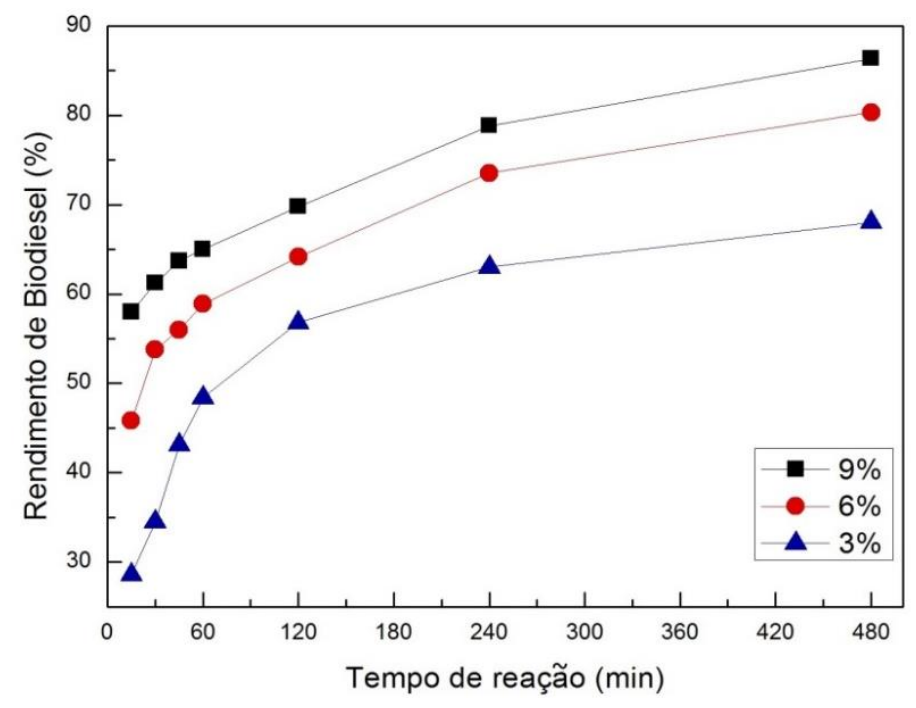




\section{CONCLUSÃO}

O objetivo principal do trabalho foi investigar a influência do excesso molar de metanol e da concentração de água adicionados na reação de transesterificação para produção de biodiesel, utilizando como catalisador a lipase Callera ${ }^{\mathrm{TM}}$ Trans L. Os experimentos realizados confirmaram que o excesso de metanol utilizado favorece a reação de transesterificação, porém foi constatado que a razão molar metanol:óleo não deve ultrapassar o valor de 4,5:1, pois em concentrações mais elevadas de álcool a inibição na atividade enzimática ocorre de forma mais acentuada, afetando o rendimento do processo. Com relação à influência da água no sistema, o melhor resultado foi alcançado utilizando $9 \%$ de água, indicando que a concentração de água desempenha um papel fundamental tanto na ativação interfacial da lipase quanto como um solvente, ao diluir o metanol e minimizando os efeitos inibitórios do álcool sobre a lipase. Além disso, os resultados também mostraram um decréscimo no rendimento de biodiesel ao utilizar concentrações superiores a $9 \%$ de água devido ao possível favorecimento da reação de hidrólise em detrimento da transesterificação.

\section{REFERÊNCIAS}

BASKAR, G.; AISWARYA, R. Trends in catalytic production of biodiesel from various feedstocks. Renewable and Sustainable Energy Reviews, v. 57, p. 496-504, 2016.

CESARINI, S.; DIAZ, P.; NIELSEN, P. M. Exploring a new, soluble lipase for FAMEs production in water-containing systems using crude soybean oil as a feedstock. Process Biochemistry, v. 48, p. 484-487, 2013.

CHRISTOPHER, L. P.; KUMAR, H.; ZAMBARE, V. P. Enzymatic biodiesel: Challenges and opportunities. Applied Energy, v. 119, p. 497-520, 2014.

MAGALHÃES, S. P. Estudo da reação de transesterificação enzimática do óleo de palma e do comportamento das fases envolvidas. Tese (Doutorado em Engenharia Química). COPPE, Universidade Federal do Rio de Janeiro, Rio de Janeiro, 2014.

NORDBLAD, M.; SILVA, V. T. L.; NIELSEN, P. M.; WOODLEY, J. M. Identification of Critical Parameters in Liquid Enzyme-Catalyzed Biodiesel Production. Biotechnology and Bioengineering, v. 111, p. 2446-2453, 2014.

SAYID ABDULLAH, S. H. Y.; HANAPI, N. H. M.; AZID, A.; UMAR, R.; HAFIZAN, J.; KHATOON, H.; ENDUT, A. A review of biomass-derived heterogeneous catalyst for a sustainable biodiesel production. Renewable and Sustainable Energy Reviews, v. 70, p. 1040-1051, 2017.

SOUSA, G. S.; BORGES, G. A.; CARVALHO, S. D.; SILVA, E. F. Catálise Enzimática: uma estratégia promissora na produção de biodiesel. Almanaque Multidisciplinar de Pesquisa, v.1, p. 159-169, 2015. 